Int. J. Electrochem. Sci., 15 (2020) $1-15$

International Journal of

ELECTROCHEMICAL

SCIENCE

WWW.electrochemsci.org

\title{
Corrosion Inhibition Performance of Coconut Leaf Extract as a Green Corrosion Inhibitor for X65 Steel in Hydrochloric Acid Solution
}

\author{
Siyi Chen", Bin Zhu, Xing Liang \\ College of Chemistry and Chemical Engineering, Zunyi Normal University, Zunyi 563002, PR China. \\ *E-mail: chensiyijiayou@163.com
}

doi: $10.20964 / 2020.01 .39$

Received: 3 September 2019 / Accepted: 30 October 2019 / Published: 30 November 2019

In this paper, coconut leaf extract was extracted with absolute ethanol. The corrosion inhibition performance of coconut extract on X65 steel in the corrosive medium of $\mathrm{HCl}$ was studied using electrochemical ways, surface morphology analysis, and theoretical calculations. Experimental data of potentiodynamic polarization curves indicated that coconut extract is a mixed-type corrosion inhibitor. Surface morphology analysis test results showed that coconut leaf extract can effectively inhibit the corrosion of X65 steel. The adsorption of coconut leaf extract on the X65 steel surface conforms to the Langmuir single layer adsorption. Quantum chemical calculations and molecular dynamics simulations can effectively demonstrate that coconut leaf extracts exhibit excellent corrosion inhibition performance.

Keyword: Coconut leaf extract; X65 steel; Corrosion inhibitor; Langmuir adsorption model; Quantum chemical calculations; Molecular dynamics simulations

\section{FULL TEXT}

(C) 2020 The Authors. Published by ESG (www.electrochemsci.org). This article is an open access article distributed under the terms and conditions of the Creative Commons Attribution license (http://creativecommons.org/licenses/by/4.0/). 